\title{
Thermal kinetics of micro-defects in He-ion implanted W and W5Re alloys
}

\author{
Yong-Li Liu ${ }^{1,2} \cdot$ Ya-Min Song ${ }^{1,2}$ - Lei Li ${ }^{1} \cdot$ Ruo-Yu Bai $^{3}$ - Peng Zhang ${ }^{1}$ - Qiao-Li Zhang ${ }^{3} \cdot$ Shuo-Xue Jin ${ }^{1} \cdot$ Te Zhu $^{1}$. \\ Er-Yang $\mathrm{Lu}^{4} \cdot$ Xing-Zhong Cao ${ }^{1,2}$ (B) Bao-Yi Wang ${ }^{1,2}$
}

Received: 9 September 2020 / Revised: 29 October 2020 / Accepted: 23 November 2020 / Published online: 19 March 2021

(c) The Author(s) 2021

\begin{abstract}
To investigate the thermal evolution of vacancy-type defects in He-ion irradiated W and W5Re alloy, different isochronal annealing treatments from 373 to $1273 \mathrm{~K}$ were conducted on the irradiated materials. Positron annihilation spectroscopy including positron annihilation lifetime spectroscopy and Doppler broadening spectroscopy were mainly used to characterize the micro-defects evolution. The results showed that the thermal evolution characteristics of defects in both W and W5Re were similar. After He-ion irradiation, mono-vacancies with positron annihilation lifetime of $\sim 190 \mathrm{ps}$ were detected in W, together with a large amount of dislocation loops with positron annihilation lifetime of $\sim 150 \mathrm{ps}$ in W5Re alloys. The coarsening of vacancy clusters at the expense of small vacancy clusters was the main thermal evolution feature of vacancy-type defects in both $\mathrm{W}$ and W5Re when annealing temperature increased to $1073 \mathrm{~K}$. In this progress, the positron annihilation lifetime increased to $\sim 350 \mathrm{ps}$ (clusters composed of 4-8 mono-vacancies) in both W and W5Re. As the temperature increased to $1273 \mathrm{~K}$, the positron annihilation lifetime decreased to $\sim 240 \mathrm{ps}$, which was attributed to a significant population reduction of the dislocation loops, the dissociation of large $\mathrm{He}_{\mathrm{n}} \mathrm{V}_{\mathrm{m}}$ complexes and the annealing of micro-voids in both W and W5Re. The vacancy-type defects in W5Re were more susceptible to the annealing temperature because of the formation of vacancy cluster-Re complexes. Re clusters in irradiated W5Re alloy could serve as the nucleation sites of He bubbles, which promoted the swelling and protrusion formation on the surface.
\end{abstract}

Keywords Tungsten $\cdot$ W5Re $\cdot$ He-ion irradiation $\cdot$ Positron annihilation spectroscopy $\cdot$ Thermal evolution characteristics

\section{Introduction}

Tungsten (W) is widely considered as the candidate for plasma facing materials (PFMs) in fusion reactor [1-3]. However, under the deuterium-tritium fusion reaction, PFMs-W has to withstand tremendous damages produced

Er-Yang Lu

eryang.lu@helsinki.fi

$\triangle$ Xing-Zhong Cao caoxzh@ihep.ac.cn

1 Positron Facility, Institute of High Energy Physics, Chinese Academy Sciences (CAS), Beijing 100049, China

2 University of Chinese Academy of Sciences, Beijing 100039, China

3 China Institute of Atomic Energy, Beijing 102413, China

4 Department of Physics, University of Helsinki, P.O. Box 43, 00014 Helsinki, Finland by high energy neutron $(\sim 14 \mathrm{MeV})$ and high thermal flux $\left(\sim 10 \mathrm{MW} \cdot \mathrm{m}^{-2}\right)$. Besides, a continuous production of helium $(\mathrm{He})$ through $(\mathrm{n}, \alpha)$ transmutation reactions in the bulk of PFMs-W are easy to be captured by irradiation-induced defects (such as vacancies, clusters, voids and dislocations) to form He-defect complexes even He bubbles during the diffusion process, leading to the degradation of the material mechanical properties including irradiation hardening and swelling $[4,5]$. Therefore, it is significant to understand the physical fundamental behind these changes introduced by fusion neutrons. However, the enough high flux of $14 \mathrm{MeV}$ neutron irradiation is not available currently. Instead of the neutron irradiation, multiple He-ion irradiation has become one of the main methods to study the irradiation damage and He behavior in PFMs simultaneously. The fusion neutrons also transform PFMs-W into transmutation rhenium (Re) element through neutron capture reactions. It is reported by many researchers that the accumulation of Re significantly threatens the lifetime of PFMs-W because of the 
deterioration of mechanical properties [4, 6-9]. In current study, the irradiation effect caused by $5 \mathrm{wt} \%$ Re addition in $\mathrm{W}$ is investigated compared to pure $\mathrm{W}$, which is considered as a possible guideline for further research on the application of W-based alloys in fusion field.

High resolution transmission electron microscopy (TEM) is preferred by many researchers to investigate the structure of neutron/ion irradiation-induced micro-defects [5, 10]. However, it is difficult to detect the defect with size smaller than $1 \mathrm{~nm}$ by TEM. The distribution and dynamic of vacancy-type defects in the implantation depth become more significant in structural material characterization, which makes it necessary to utilize the positron annihilation spectroscopy (PAS). PAS is an effective and convenient technique to study the irradiation-induced vacancy-type defects, such as vacancy, vacancy cluster, vacancy-type dislocation loops as well as vacancy-impurity complex [11-14]. Positron is exclusively sensitive to vacancies, providing information of the size, density and depth distribution of vacancy-type defects $[3,15,16]$. Sato et al. [17] took the PAS technique to study the change of the hydrogen decorated vacancies in Ogorodnikova et al. [18] applied the PAS to investigate $\mathrm{W}$ exposed to $21.6 \mathrm{MeV}$ protons and found that proton irradiation mainly induced the mono-vacancies. Mono-vacancies started to migrate at $\sim 473 \mathrm{~K}$ in He-irradiated W [13]. High temperature promoted the vacancy clustering along the three-dimensional direction and the formation of micro-voids. The collapse of some micro-voids leads to the production of vacancy-type dislocation loops which begin to anneal at $\sim 1023 \mathrm{~K}$. These evaluation progresses resulted in a change of the positron annihilation lifetime [13, 19]. Based on the mechanism of positron capture and annihilation, the types of defects and the chemical information of elemental changes could be explored, especially the basic information of the element-defects complex structures.

\section{Experimental}

Polycrystalline W (99.95 wt\%) and W5Re alloys (W-5 wt $\%$ Re) were supplied by Advanced Technology \& Materials Co., Ltd. (AT\&M). After mechanical and electrochemical polishing, all samples were thermally annealed at $1373 \mathrm{~K}$ with the duration of $2 \mathrm{~h}$ in vacuum $\left(\sim 10^{-5} \mathrm{~Pa}\right)$.
He-ion irradiation at room temperature (RT) was performed on a $200 \mathrm{kV}$ ion implanter. More details of He-ion irradiation are shown in Table 1 . The sequential He-ion irradiation of $16 \mathrm{keV}, 70 \mathrm{keV}$ and $200 \mathrm{keV}$ on W-3 and W5Re-3 was determined to simulate the neutron average damage distribution in bulk layer of 0-500 nm. He-ion flux ranged from $(0.42-1.72) \times 10^{13} \mathrm{~cm}^{-2} \cdot \mathrm{s}^{-1}$, which made the displacement damage up to $0.83 \mathrm{dpa}$ (displacement per atom) for W-1 and W5Re-1, 1.62 dpa for W-2 and W5Re-2, and 1.45 dpa for $\mathrm{W}-3$ and W5Re-3. Isochronal $\left(1 \mathrm{~h}, \sim 5.5 \times 10^{-5} \mathrm{~Pa}\right)$ thermal annealing was performed on all irradiated samples at $373 \mathrm{~K}$, $573 \mathrm{~K}, 673 \mathrm{~K}, 773 \mathrm{~K}, 873 \mathrm{~K}, 1073 \mathrm{~K}$ and $1273 \mathrm{~K}$. Following each annealing process, the samples were naturally cooled down and characterized by positron annihilation lifetime spectroscopy (PALS) and Doppler broadening spectroscopy (DBS) at RT.

\section{Characterization methods}

As a sensitive probe to vacancies, positron can be effectively captured by vacancy-type defects. In the process of annihilation with electrons, $\gamma$ rays carrying the information of microstructure and chemical environment at the position annihilation site are produced [19-23]. The time interval between the production of the $0.511 \mathrm{MeV}-\gamma$-ray and the emission of the $1.28 \mathrm{MeV}-\gamma$-ray is regarded as the positron annihilation lifetime, which is closely related to the electron density where the annihilation occurs. The radioactivity of the ${ }^{22} \mathrm{Na}$ source used in PALS measurement is $\sim 0.185 \mathrm{MBq}$ and the time resolution of associated $\mathrm{BaF}_{2}$ detector is $\sim 195 \mathrm{ps}$. The source is encapsulated by Kapton films with thickness of $\sim 7 \mu \mathrm{m}$, which is sandwiched between two samples to be detected.

The DBS based on low positron beam with a positron source of ${ }^{22} \mathrm{Na}$ (45 mCi in 2016) were carried on all samples. The fast positrons from source are thermalized by the moderator of multi-layer $\mathrm{W}$ nets, and then thermally emit from moderator's surface with a certain kinetic energy $(\sim 2.1 \mathrm{eV})$. A negative high voltage is applied to the sample target to realize the continuous adjustment of positron energy in the range of $0.18-20.18 \mathrm{keV}$. The mean incident depth $Z(\mathrm{~nm})$ of low-energy mono-energetic positrons in target follows the empirical equation
Table $1 \mathrm{He}$-ion irradiation details

\begin{tabular}{llll}
\hline Sample (name-number) & $\begin{array}{l}\text { He-ion irradiation energy }(\mathrm{keV}) \text { and fluence } \\
(\text { ion.cm }\end{array}$ & $\begin{array}{l}\text { He-ion irra- } \\
\text { diation damage } \\
(\mathrm{dpa})\end{array}$ & $\begin{array}{l}\text { He-ion } \\
\text { concentration } \\
\text { (at.\%) }\end{array}$ \\
\hline W-1 and W5Re-1 & $16 \& 5.8 \mathrm{E} 16$ & 0.83 & 10.81 \\
W-2 and W5Re-2 & $200 \& 2.4 \mathrm{E} 17$ & 1.62 & 13.95 \\
W-3 and W5Re-3 & $200 \& 2.4 \mathrm{E} 17 \rightarrow 70 \& 1 \mathrm{E} 17 \rightarrow 16 \& 5.8 \mathrm{E} 16$ & $\sim 1.45$ & $\sim 10$ \\
\hline
\end{tabular}


$Z=40 \times E^{1.6} / \rho$,

where $E$ is the positron energy $(\mathrm{keV}), \rho$ is the material density $\left(\mathrm{g} \cdot \mathrm{cm}^{-3}\right)$. The positron-electron pair annihilation producing $\gamma$ rays especially those with energy from $505.1-508.4 \mathrm{keV}$ are recorded by a high-purity germanium detector with an energy resolution of $1.2 \mathrm{keV}$ at $511 \mathrm{keV}$. The number of photons recorded in intermediate-energy window (510.2-511.8 keV) in Doppler spectrum is the annihilation contribution between positron and low-momentum valence electron in target, which determines $S$ parameter. The number of photons recorded in the both two energy windows (503.3-507.2 keV and 514.8-518.7 keV) in Doppler spectrum comes from the annihilation contribution of positron and high-momentum core electron in target, which determines the $W$ parameter $[24,25]$. The $S$ parameter is sensitive to the open volume defects and $W$ parameter is most probably related to the chemical surrounding at the annihilation sites. The depth dependence of the positron annihilation parameters is denoted by $S-E$ or $W-E$ profiles.

\section{Results and discussion}

\subsection{SRIM simulation}

Using the stopping and range of ions in matter (SRIM) computer program [26], the He-ion irradiation damage (dpa) and $\mathrm{He}$ atom concentration (at.\%) as a function of positron penetration depth $(\mathrm{nm})$ were predicted in both $\mathrm{W}$ and W5Re, as shown in Fig. 1. "Full Cascade" mode was selected as the calculation type. The displacement threshold energy was $90 \mathrm{eV}$ and the lattice binding energy was $3 \mathrm{eV}$ for both $\mathrm{W}$ and W5Re alloy [27]. W5Re plots are not exhibited in

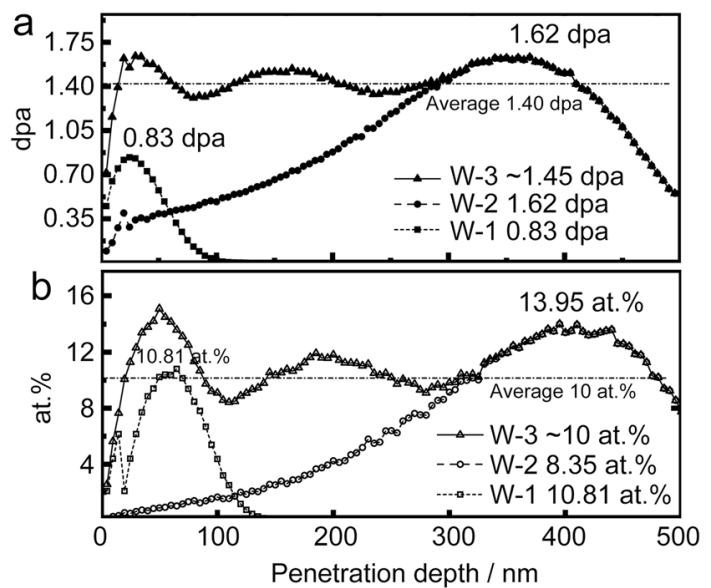

Fig. 1 a He-ion irradiation damage (dpa) in W-1, W-2, and W-3 and b the corresponded $\mathrm{He}$ atom concentration (at.\%) as a function of positron penetration depth $(\mathrm{nm})$ with SRIM calculations
Fig. 1, because of the marginal differences of material density between $\mathrm{W}$ and W5Re alloys. The displacement damage and $\mathrm{He}$ atom concentration was $0.83 \mathrm{dpa}$ and 10.81 at.\% at $25 \mathrm{~nm}$ for W-1 and W5Re-1, $1.62 \mathrm{dpa}$ and 13.95 at.\% at $34 \mathrm{~nm}$ for $\mathrm{W}-2$ and $\mathrm{W} 5 \mathrm{Re}-2$, and $1.45 \mathrm{dpa}$ and 10 at.\% from surface to $500 \mathrm{~nm}$ for W-3 and W5Re-3. The data is listed in Table 1.

\subsection{Evolution of the type and associated intensities of the vacancy-type defects}

In order to study the thermal evolution of irradiation-induced vacancy-type defect, PALS measurements were carried out on W-1, 2, 3 and W5Re-1, 2, 3. The PALS spectra with a total count of $2 \times 10^{6}$ were analyzed by LT-9.0 program [28]. It should be noted that a small fraction $(\sim 4.57 \%)$ of positrons from the ${ }^{22} \mathrm{Na}$ source (average energy of the emitted positrons is $\sim 260 \mathrm{keV}$ ) annihilated in the depth range within $500 \mathrm{~nm}$. The advantage of positron self-searching for vacancy-type defects makes more positrons annihilate in irradiation-induced region. Besides, $\mathrm{W}$ has a large (absolute value) positron negative work function $(-2.1 \mathrm{eV})$. Therefore, the experimental results show that some qualitative assessment can be still performed as the vacancytype defects detected by positrons which are expected to be exclusively from the implanted region. The intensity of the defect component is, however, meaningless without a precise assessment of the fraction of signal coming from unirradiated bulk. So the relative variation of intensity would be discussed.

The PALS characterization data of W and W5Re alloys is listed in Tables 2 and 3, respectively. The source contribution in Kapton films was $20 \%$ and the lifetime component was 382 ps. The PALS spectra of He-ion irradiated sample were decomposed by three lifetime components: $\tau_{1}, \tau_{2}$ and $\tau_{3}$. Here, $\tau_{3}$ is the positron annihilation lifetime of the orthopositronium in sample surface and even in the sample-film interface [29]. The intensity of $\tau_{3}$ is extremely small $(<1 \%)$ and commonly keep constant in PALS characterization for different metals, and therefore $\tau_{3}$ is not listed in Tables 2 and 3. Positrons are annihilated in free state with electrons in perfect crystal regions, which are easy to be captured by vacancy-type defects (such as vacancies, dislocation loops, and vacancy clusters.) in ion-irradiated materials. $\tau_{1}$ is the positron annihilation lifetime in the "free" Bloch state which is in general less than the positron annihilation lifetime in perfect lattice. $\tau_{2}$ is the positron annihilation lifetime at the vacancy-type defect sites, and its variation provides significant information on the kinetics of irradiation-induced defects. $I_{1}$ and $I_{2}$ are the intensities of defects with $\tau_{1}$ and $\tau_{2}$. $\tau_{\mathrm{m}}$ is conducted by the equation 
Table 2 PALS results of the well-annealed $\mathrm{W}$ and $\mathrm{He}$-ion irradiated W-1 (0.83 dpa), W-2 (1.64 dpa) and W-3 $(\sim 1.45 \mathrm{dpa})$. The irradiated samples were subjected to isochronal thermal annealing under $673 \mathrm{~K}, 773 \mathrm{~K}, 873 \mathrm{~K}$, $1073 \mathrm{~K}$ and $1273 \mathrm{~K}$ for $1 \mathrm{~h}$, respectively
Table 3 PALS results of well-annealed W5Re and He-ion irradiated W5Re-1 (0.83 dpa), W5Re-2 (1.64 dpa) and W5Re-3 ( 1.45 dpa). The irradiated samples were subjected to isochronal thermal annealing under $673 \mathrm{~K}, 773 \mathrm{~K}$, $873 \mathrm{~K}, 1073 \mathrm{~K}$ and $1273 \mathrm{~K}$ for 1 $\mathrm{h}$, respectively

\begin{tabular}{lcllcll}
\hline Sample & $\tau_{1}(\mathrm{ps})$ & $I_{1}(\%)$ & $\tau_{2}(\mathrm{ps})$ & $I_{2}(\%)$ & $\tau_{\mathrm{m}}(\mathrm{ps})$ & Fitted factor \\
\hline W annealed & $118.35 \pm 0.21$ & $99.676 \pm 0.031$ & - & - & $118.35 \pm 0.21$ & 1.13 \\
W-1-RT & $101.02 \pm 0.23$ & $86.17 \pm 0.71$ & $197.1 \pm 5.5$ & $13.5 \pm 0.71$ & $114.03 \pm 0.94$ & 0.93 \\
W-1-673K & $115.74 \pm 0.72$ & $84.94 \pm 0.38$ & $355.3 \pm 7.1$ & $14.34 \pm 0.38$ & $150.34 \pm 1.64$ & 1.05 \\
W-1-773K & $113.82 \pm 0.24$ & $83.34 \pm 0.073$ & $340.7 \pm 2.6$ & $15.757 \pm 0.063$ & $149.89 \pm 0.62$ & 0.99 \\
W-1-873K & $112.6 \pm 0.85$ & $84.62 \pm 0.39$ & $339.3 \pm 7.7$ & $14.81 \pm 0.38$ & $146.44 \pm 1.87$ & 1.00 \\
W-1-1073K & $120.20 \pm 1.2$ & $81.68 \pm 0.66$ & $320.3 \pm 8.2$ & $17.55 \pm 0.66$ & $155.59 \pm 2.44$ & 1.04 \\
W-1-1273K & $100.81 \pm 0.52$ & $82.36 \pm 0.78$ & $228.2 \pm 5.5$ & $17.41 \pm 0.78$ & $123.04 \pm 1.39$ & 1.01 \\
W-2-RT & $105.6 \pm 2.9$ & $75.6 \pm 3.2$ & $193 \pm 8.9$ & $24.1 \pm 3.2$ & $126.73 \pm 4.35$ & 0.93 \\
W-2-673K & $122.54 \pm 0.63$ & $80.92 \pm 0.43$ & $317.4 \pm 6.7$ & $18.1 \pm 0.43$ & $158.16 \pm 1.74$ & 0.98 \\
W-2-773K & $119.22 \pm 0.74$ & $79.51 \pm 0.39$ & $308.2 \pm 5$ & $19.58 \pm 0.38$ & $156.56 \pm 1.58$ & 0.89 \\
W-2-873K & $124.3 \pm 1.1$ & $82.39 \pm 0.58$ & $332 \pm 8.2$ & $16.71 \pm 0.58$ & $159.32 \pm 2.3$ & 1.04 \\
W-2-1073K & $125.9 \pm 1.2$ & $82.52 \pm 0.67$ & $330.4 \pm 9.1$ & $16.72 \pm 0.67$ & $160.35 \pm 2.53$ & 0.96 \\
W-2-1273K & $103.22 \pm 0.94$ & $83.24 \pm 0.66$ & $241.9 \pm 4.4$ & $16.45 \pm 0.66$ & $126.1 \pm 1.51$ & 0.96 \\
W-3-RT & $97.80 \pm 0.43$ & $68.76 \pm 0.79$ & $181.4 \pm 2.3$ & $30.94 \pm 0.79$ & $123.74 \pm 1.01$ & 0.96 \\
W-3-673K & $122.30 \pm 1.1$ & $81.65 \pm 0.61$ & $327.8 \pm 7.7$ & $17.5 \pm 0.61$ & $158.57 \pm 2.26$ & 1.03 \\
W-3-773K & $121.34 \pm 0.95$ & $80.6 \pm 0.55$ & $327.5 \pm 6.1$ & $18.67 \pm 0.55$ & $160.11 \pm 1.92$ & 1.03 \\
W-3-873K & $120.30 \pm 1$ & $79.57 \pm 0.47$ & $324.1 \pm 6$ & $19.27 \pm 0.47$ & $160.03 \pm 1.97$ & 0.99 \\
W-3-1073K & $127.47 \pm 0.79$ & $84.13 \pm 0.41$ & $349.8 \pm 6.7$ & $15.19 \pm 0.41$ & $161.47 \pm 1.69$ & 0.94 \\
W-3-1273K & $108.82 \pm 0.42$ & $77.12 \pm 0.53$ & $235.5 \pm 3.7$ & $22.33 \pm 0.54$ & $137.26 \pm 1.16$ & 1.11 \\
\hline & & & & & &
\end{tabular}

$\tau_{\mathrm{m}}=\left(\tau_{1} I_{1}+\tau_{2} I_{2}\right) /\left(I_{1}+I_{2}\right)$

which represents the mean positron annihilation lifetime of the effective open volume defects in the whole sample [3, 30]. As shown in Tables 2 and 3, the free state positron annihilation intensity reached $\sim 99 \%$ in both well-annealed $\mathrm{W}$ and W5Re. $\tau_{\mathrm{m}}$ is $\sim 118 \mathrm{ps}$ for the well-annealed $\mathrm{W}$, which is close to the mean positron annihilation lifetime ( $\sim 120 \mathrm{ps})$ in defect-free $\mathrm{W}$ [31]. The addition of $5 \mathrm{wt} \%$ Re element in $\mathrm{W}$ prolongs the mean-lifetime to 134 ps in well-annealed W5Re alloys.

Figure 2 shows the positron annihilation lifetimes $\left(\tau_{1}, \tau_{2}\right.$ and $\left.\tau_{\mathrm{m}}\right)$ and the intensities $\left(I_{2}\right)$ as functions of annealing temperature from RT to $1273 \mathrm{~K}$. After irradiation, an obvious 
lifetime component $\tau_{2}$ appeared in both $\mathrm{W}$ and W5Re alloys. The impact of thermal annealing on the positron annihilation lifetime is remarkable. The $\tau_{\mathrm{m}}$ of $\mathrm{W}$ and W5Re alloy of different doses and energy has similar thermal evolution characteristics. The $\tau_{2}$ with the number of 197 ps, 193 ps and 181 ps is produced in irradiated W-1, W-2 and W-3, respectively. They are close to the lifetime $\sim 180$ ps of positron annihilation in mono-vacancies [32]. However, smaller number of $\tau_{2}(\sim 140 \mathrm{ps})$ with larger intensity is observed in irradiated W5Re alloys than that in W. It is reported that the positron annihilation lifetime at dislocation loops is $\sim 150 \mathrm{ps}$ in pure W [13]. The dislocation loops with size larger than $2 \mathrm{~nm}$ are observed in neutron-irradiated W [19]. Many literatures have reported that the addition of Re decreased the energy barrier which was account for a high yield of dislocation loops [7, 9, 33, 34]. Thus, it can be referred that a large number of dislocation loops are introduced into W5Re alloy under RT-He-ion irradiation. As the annealing temperature increased to $673 \mathrm{~K}$, both $\tau_{1}$ and $\tau_{2}$ are elevated to $120 \mathrm{ps}$ and 350 ps for W and W5Re alloys, respectively, as shown in Fig. 2. Nambissan et al. [13] has reported that an increasing number of positrons were trapped by vacancies when the annealing temperature reached $573 \mathrm{~K}$. In this case, the vacancies may come from the displacement cascade damage and the dissociation of the vacancy-helium complexes. The migration and coalescence of mono-vacancies and di-vacancies directly promote the production of small vacancy clusters. After $673 \mathrm{~K}$ annealing process, the decomposed second lifetime component $\tau_{2}$ increases to $\sim 350 \mathrm{ps}$ combined with the sharp decrement of the intensity $\left(I_{2}\right)$. The strong population reduction of vacancy clusters is presumably consistent with the growth of large vacancy clusters at the expense of

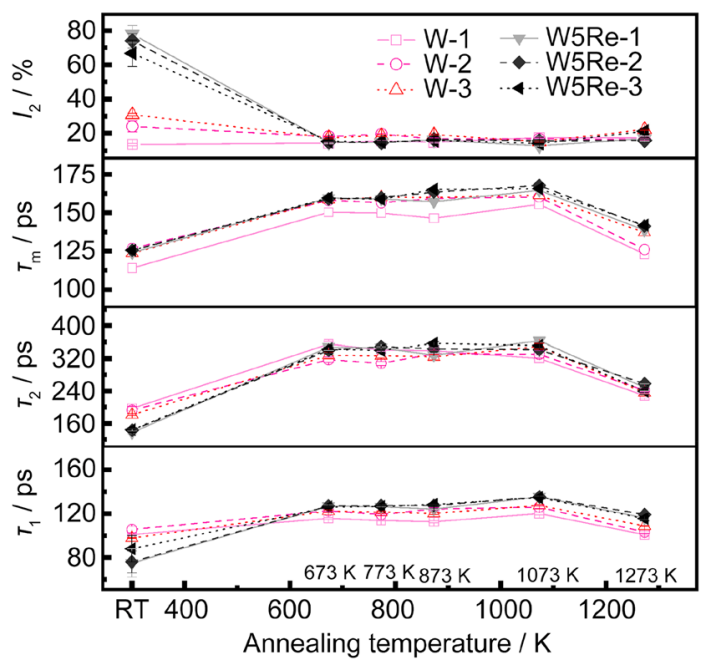

Fig. 2 Positron annihilation lifetimes (the short-lifetime $\tau_{1}$, the longlifetime $\tau_{2}$ and the mean-lifetime $\left.\tau_{\mathrm{m}}\right)$ and the intensities $\left(I_{2}\right)$ as function of annealing temperature from RT to $1273 \mathrm{~K}$ small vacancy clusters. There is a little deviation of the positron annihilation lifetime components in the region from 673 to $1073 \mathrm{~K}$. The $\tau_{2}$ around $350 \mathrm{ps}$ is the positron annihilation lifetime in the three-dimensional vacancy clusters composed of 4-8 mono-vacancies [35]. High temperature heating promotes the continuous growth of vacancy clusters, leading to the possibly formation of micro-voids with a decreasing intensity which are still the effective trapping site of positron. It was reported that the number of the dislocation loops decreased about one order of magnitude when the annealing temperature increased from 773 to $1073 \mathrm{~K}$ [19]. At $1273 \mathrm{~K}$ annealing, the $\tau_{2}$ decreases significantly to $\sim 240 \mathrm{ps,} \mathrm{which}$ is due to the significant decrease of the dislocation loops in the samples [36]. At this temperature, the number density of the line dislocations is much lower than that of the dislocation loops. In addition, the grain boundaries act as the sinks for vacancies to release themselves below $1073 \mathrm{~K}$. It directly reduces the nucleation points of the micro-voids at 1273 K. Similar conclusions were drawn in Ref. [13] that micro-voids in polycrystalline $\mathrm{W}$ tend to be annealed by the grain boundary effect between 1023 and $1323 \mathrm{~K}$.

\subsection{Depth distribution of vacancy-type defects in thermal annealed W and W5Re alloys}

Figures 3 and 4 show the thermal evolution of $S$ and $W$ parameters in W-1, 2, 3 and W5Re-1, 2, 3 with the increasing incident positron energy, respectively. The data of the well-annealed and post-irradiated samples has been added into the figures. The $S$ (versus $W$ ) parameter in the matrix of well-annealed $\mathrm{W}$ is $\sim 0.425$ (0.09), while the peak position of $S$ - $E$ profile of post-irradiated W-1 is at $\sim 10 \mathrm{~nm}$ from the surface, and the $W$ parameter has a minimum value at the same position. When the annealing temperature is increased to $1273 \mathrm{~K}$, the $S$ parameter of $\mathrm{W}-1$ varies significantly in the range of $0-27 \mathrm{~nm}$. After annealing at $1273 \mathrm{~K}$, the $S-E$ peak of W-1 shifts to the bulk and the $S$ parameter increases remarkably from 27-249 nm. Compared with the $200 \mathrm{keV}$ ion irradiated $\mathrm{W}-2$, the $S$ parameters of the sequential-ion irradiated $\mathrm{W}-3$ are reduced in the range of $58-249 \mathrm{~nm}$, as shown in Fig. $3 b$ and c. This is due to the trapping of He atom at vacancy-type defects and the formation of vacancyhelium complexes [3, 10]. A turning point between 1073 and $1273 \mathrm{~K}$ is observed in all figures, which will be discussed later. Because of the epithermal positron emissions at the surface, the non-elastically scattered positron and the local changes of the surface dipole, the surface $S$ parameters of W and W5Re are relatively high in both single- or sequentialion irradiation [23, 37].

From Fig. 4, the $S$ (versus $W$ ) parameter in the matrix of well-annealed W5Re is $\sim 0.43(0.08)$, which is slightly higher than that of $\mathrm{W}$ matrix in Fig. 3, which is due to the different atomic size of $\mathrm{Re}$ and $\mathrm{W}$ atoms. The atomic volume 


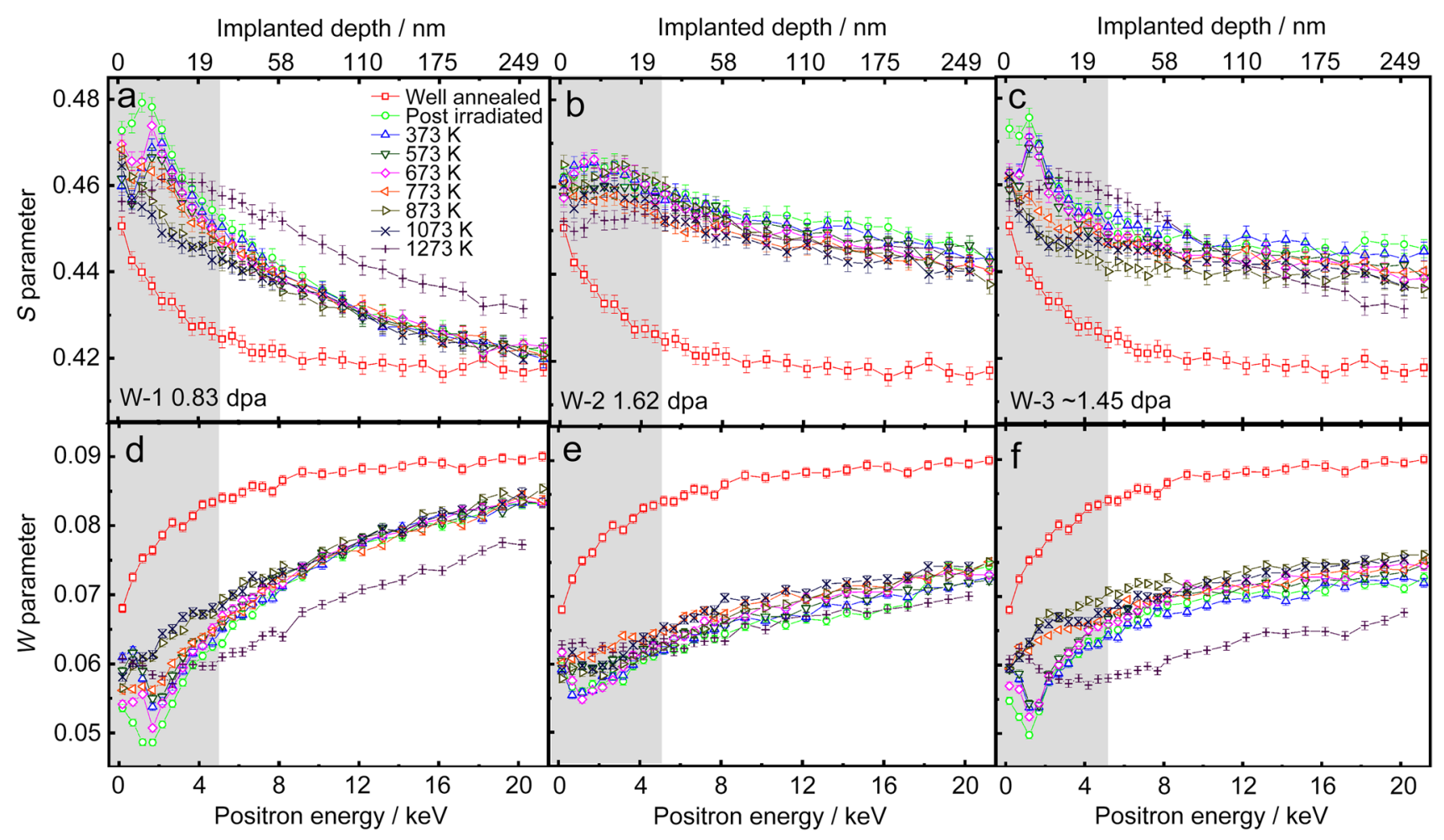

Fig. 3 a-c $S-E$ profiles and d-f $W-E$ profiles of isochronal thermal annealing W-1, W-2 and W-3 at $373 \mathrm{~K}, 573 \mathrm{~K}, 673 \mathrm{~K}, 773 \mathrm{~K}, 873 \mathrm{~K}$, $1073 \mathrm{~K}$, and $1273 \mathrm{~K}$ for $1 \mathrm{~h}$, respectively. For comparison, the $S-E$

of Re is smaller than that of $\mathrm{W}$, leading to a slight lattice distortion (contraction) in W5Re alloys during the irradiation (the atomic volumes are $15.85 \times 10^{-27} \mathrm{~nm}^{3}$ for $\mathrm{W}$ and $14.70 \times 10^{-27} \mathrm{~nm}^{3}$ for Re) $[25,38]$. The thermal evaluation of vacancy-type defects in W5Re alloys is similar to that in $\mathrm{W}$ within the region of $0-27 \mathrm{~nm}$. However, from 27 to $249 \mathrm{~nm}$, the defects in W5Re alloys are more susceptible to the annealing temperature. It is reported that the microstructural development of neutron irradiated W-Re alloys in high flux isotope reactor (HFIR) is suppressed by the accumulation of transmutation solid Re [6]. What's more, irradiation induced vacancies, dislocations or vacancy clusters are likely to act as the strong trapping sites for Re atoms [9, 34, 39]. Therefore, due to the pinning effect of Re clusters, the Re atom would suppress the growth and migration of vacancies to a certain extent. The increasing thermal evolution temperature may promote the formation of these vacancy clusters-Re complexes, reducing the positron annihilation fraction at the open volume sites.

The $S-E$ curves show obvious and regular thermal evaluation characteristics of $S$ parameter in the shallow layer of $0-27 \mathrm{~nm}$ and the intermediate layer of 27-249 $\mathrm{nm}$ for both $\mathrm{W}$ and W5Re. Through the formula of and $W-E$ profiles of the well-annealed $\mathrm{W}$ and post-irradiated $\mathrm{W}$ were included. The top axis was the corresponding positron implantation depth. The shadow region was from $0-27 \mathrm{~nm}$

$\Delta S=S_{\text {irra }}-S_{\text {non }}$,

where the $\Delta S$ is the net $S$ parameter, $S_{\text {irra }}$ is the irradiation induced $S$ parameter and the $S_{\text {non }}$ is the well-annealing induced $S$ parameter, the $\Delta S$ which weakens the influence of intrinsic defects can be obtained as a function of positron implantation energy $(\Delta S-E)$. Figure 5 shows the temperature dependence of average $\Delta S\left(\Delta S_{\text {ave }}\right)$ parameters in the depth regions of 0-27 nm (SIR: shallow implanted region) and 27-249 nm (IIR: intermediate implanted region) of $\mathrm{W}$ and W5Re, respectively.

The $\Delta S_{\text {ave }}$ parameter in SIR presents an obvious zigzag decline compared with that in IIR from RT (post-irradiated) to $1073 \mathrm{~K}$ which is defined as "negative slope stage". From $1073-1273 \mathrm{~K}$, the $S$ parameter increases markedly which is defined as "positive slope stage". The negative slope stage is related to the aggregation and growth of vacancy-type defects which is at a large cost of the population of small vacancy clusters. It can be seen from Fig. 5a that the $\Delta S_{\text {ave }}$ parameters of all samples in SIR increase first and then decrease with the annealing temperature increasing from 573 to $773 \mathrm{~K}$, which are shown by the red dot arrows in Fig. $5 \mathrm{a}$. In contrast, the turning point at $673 \mathrm{~K}$ is not obvious in 


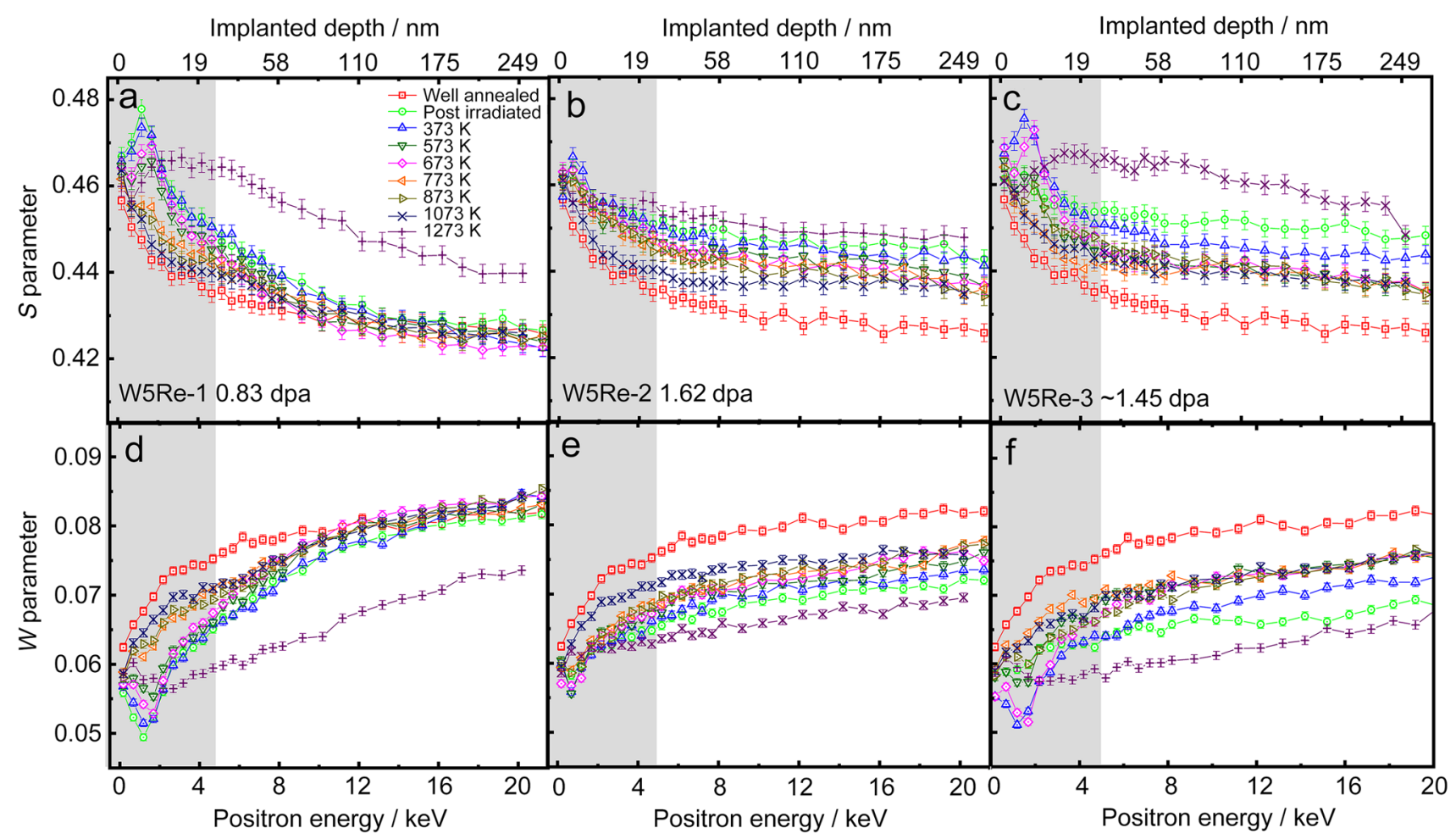

Fig. 4 a-c $S-E$ profiles and d-f $W$ - $E$ profiles of isochronal thermal annealing W5Re-1, W5Re- 2 and W5Re- 3 at $373 \mathrm{~K}, 573 \mathrm{~K}, 673 \mathrm{~K}$, $773 \mathrm{~K}, 873 \mathrm{~K}, 1073 \mathrm{~K}$, and $1273 \mathrm{~K}$ for $1 \mathrm{~h}$, respectively. For compari- son, the $S-E$ and $W-E$ profiles of the well-annealed W5Re and postirradiated W5Re were included. The top axis was the corresponding positron implantation depth. The shadow region was from 0 to $27 \mathrm{~nm}$
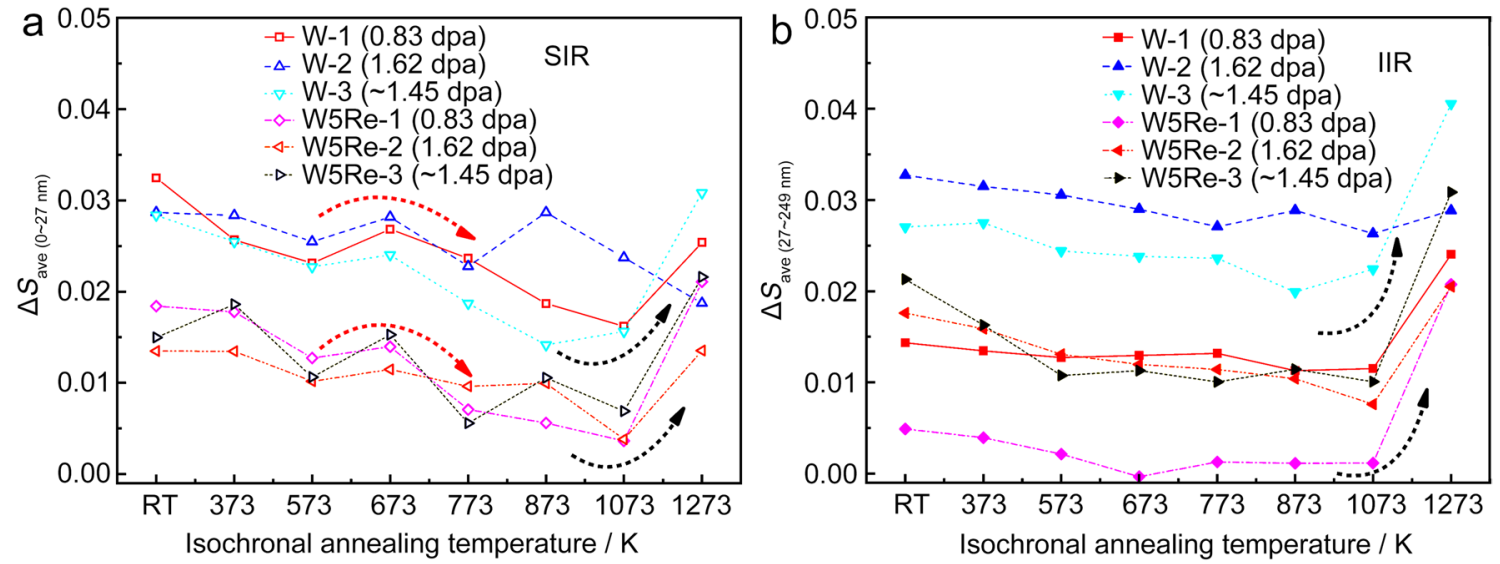

Fig. 5 Temperature dependence of $\Delta S_{\text {ave }}$ parameter in the depths of a 0-27 nm (SIR: shallow implanted region) and b 27-249 nm (IIR: intermediate implanted region) in $\mathrm{W}$ and $\mathrm{W} 5 \mathrm{Re}$ alloys

IIR. It can be predicted that the number density and size of vacancy-type defects change more obviously in near surface layer at $673 \mathrm{~K}$. It is reported that the nature of the vacancytype defects changes at $623 \mathrm{~K}$ because the clustering of mono-vacancies already occurred during the migration to the surface when the temperature was lower than $623 \mathrm{~K}$ [40]. The growth of the intermediate- or large-size clusters at expense of small size clusters were dominated above $673 \mathrm{~K}$ [19]. For most samples, the minimum value of $S$ parameter is obtained at $1073 \mathrm{~K}$ in both SIR and IIR. As the extremely 
low diffusion barrier of $\mathrm{He}(\sim 0.02 \mathrm{eV})$ in $\mathrm{W}$ promotes the diffuse rapidly to the dislocations to form the He clustersdislocation complexes at high temperature of 798-1198 K [41, 42]. Especially, the screw dislocation nodal points were reported to be the most probable nucleation sites of He bubbles [43]. All of these could lead to a decrease of the positron trapping probability at $1073 \mathrm{~K}$ annealing, even though large-sized vacancy clusters $(\sim 360 \mathrm{ps})$ were determined by PALS in this case. The positive slope stage is related to the recovery of small size vacancy-type defects. The $S$ parameter in both SIR and IIR increases sharply at $1273 \mathrm{~K}$ annealing, as shown by the black dot arrows in Fig. 5. At the same temperature, the second lifetime component $\tau_{2}$ decreases to 240 ps which is still larger than 190 ps (mono-vacancies) in both W and W5Re. The recovery of vacancies and small dislocation loops reduces the nucleation points of large vacancy clusters. On the other hand, the dissociation of the unstable $\mathrm{He}_{\mathrm{n}} \mathrm{V}_{\mathrm{m}}$ clusters and collapse of micro-voids into small size clusters with high number density may lead to an increase of $S$ parameters. It should be noted that the thermal evolution of vacancy clusters is a competitive consequence of the shrink of the open volume size and the growth of the open volume density $[19,44]$.
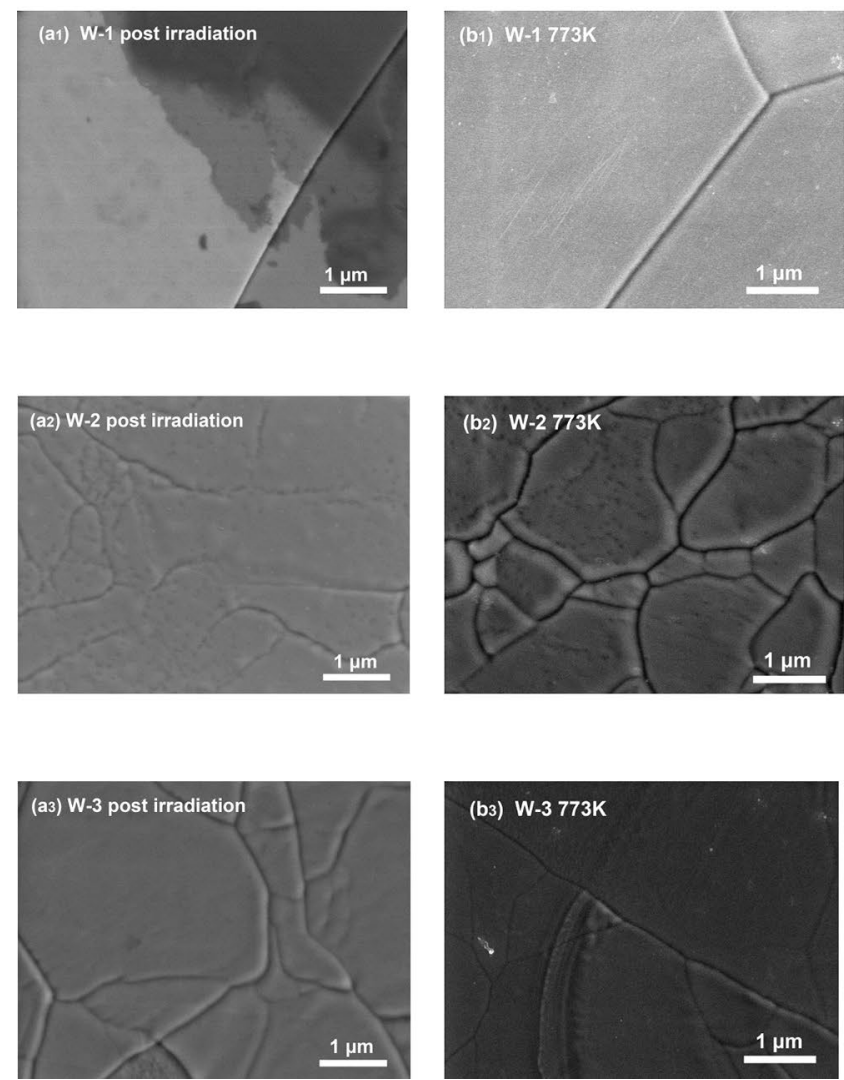
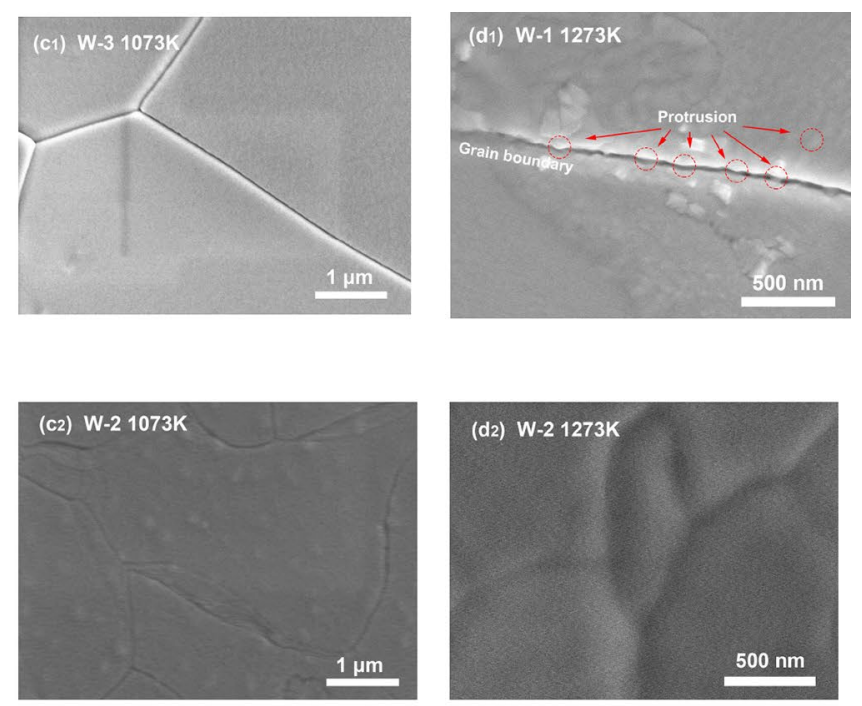

\subsection{Surface morphology of W and W5Re alloys at varied annealing processes}

From the previous analysis, it can be inferred that the irradiation-induced defects present obvious thermal evolution characteristics in the range of RT-673 K, 673-1073 K and 1073-1273 K. Figures 6 and 7 show the surface morphologies of W-1, 2, 3 and W5Re-1, 2, 3 after He-ion irradiation and subsequent isochronal thermal annealing at $773 \mathrm{~K}$, $1073 \mathrm{~K}$ and $1273 \mathrm{~K}$, respectively. The surface of post-irradiated $\mathrm{W}$ is smooth with clear grain boundary, compared with that of post-irradiated W5Re. Evidently, the grain of W5Re alloy is refined due to the addition of Re in matrix. No obvious surface plastic deformations are observed in $\mathrm{W}$ and W5Re alloy until $1073 \mathrm{~K}$ annealing. The similar conclusion was drawn that no dislocation lines or dislocation loops existed at $773 \mathrm{~K}$ and $1073 \mathrm{~K}$ under TEM observation of the neutron-irradiated W [19]. However, when the annealing temperature reaches $1273 \mathrm{~K}$, the clear protrusions (indicated by red solid arrows) are distributed at/near the grain boundaries in $\mathrm{W}$ and $\mathrm{W} 5 \mathrm{Re}$, especially in the samples irradiated by $16 \mathrm{keV}$ He ions, as shown in Figs. $6 \mathrm{~d}_{1}, 6 \mathrm{~d}_{3}$ and $7 \mathrm{~d}_{1}-\mathrm{d}_{3}$. Zhou et al. [45] also found the obvious bulges and protrusions with size of $\sim \mu \mathrm{m}$ which were proved to be blisters on the surface
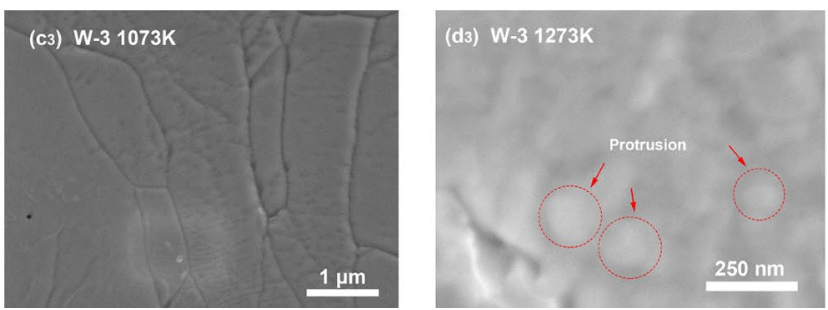

Fig. 6 SEM images of W-1, 2, 3 with $\mathbf{a}_{\mathbf{1}}-\mathbf{a}_{3}$ irradiation, followed by $\mathbf{b}_{\mathbf{1}}-\mathbf{b}_{3} 773 \mathrm{~K}$ annealing, $\mathbf{c}_{\mathbf{1}}-\mathbf{c}_{\mathbf{3}} 1073 \mathrm{~K}$ annealing and $\mathbf{d}_{\mathbf{1}}-\mathbf{d}_{\mathbf{3}} 1273 \mathrm{~K}$ annealing 

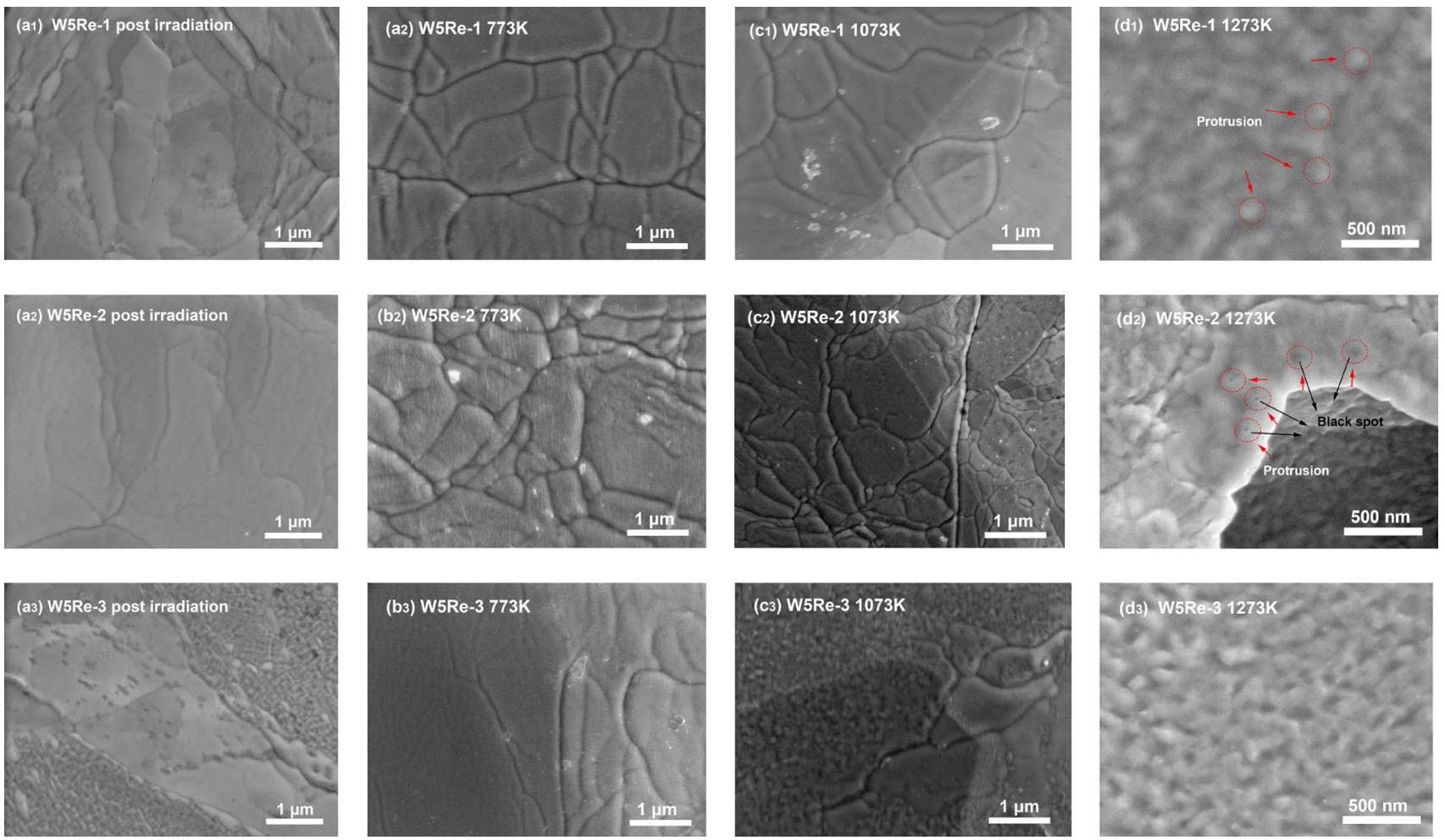

Fig. 7 SEM images of W5Re-1, 2, 3 with $\mathbf{a}_{\mathbf{1}}-\mathbf{a}_{\mathbf{3}}$ irradiation, followed by $\mathbf{b}_{\mathbf{1}}-\mathbf{b}_{\mathbf{3}} 773 \mathrm{~K}$ annealing, $\mathbf{c}_{\mathbf{1}}-\mathbf{c}_{\mathbf{3}} 1073 \mathrm{~K}$ annealing and $\mathbf{d}_{\mathbf{1}}-\mathbf{d}_{\mathbf{3}} 1273 \mathrm{~K}$ annealing

of $\mathrm{He}^{2+}$ irradiated $\mathrm{W}$ and W-5Ta alloys. It was explanted by the relaxation of stresses in $\mathrm{W}$ in terms of the enhancement of point defects diffusion in blister caps during irradiation. The surface plastic deformation is more obvious in W5Re-2 and W5Re-3, as shown in Fig. $7 \mathrm{~d}_{2}$ and $\mathrm{d}_{3}$, accompanied by the unclear grain boundaries and the large protrusions with black spots (indicated by black arrows) near the boundary [46]. These black spots are speculated to be break of the blisters-like protrusion. Many studies [13, 40, 45, 46] reported that $\mathrm{He}$ atoms begin to release from the He clusters and dislocation loops near $\mathrm{He}_{\mathrm{n}} \mathrm{V}_{\mathrm{m}}$ complexes below $573 \mathrm{~K}$ in $\mathrm{W}$. As the temperature is elevated to $773 \mathrm{~K}$, particular vacancy containing the high ratio of He atoms becomes the main site of He desorption. When reaching $973 \mathrm{~K}$, He were mainly released from the $\mathrm{He}_{\mathrm{n}} \mathrm{V}_{\mathrm{m}}$ complexes. The desorption temperature increased up to $140 \mathrm{~K}$ when formation of stable $\mathrm{He}_{\mathrm{n}} X_{\mathrm{m}} \mathrm{V}_{1}(X$ represents the solid foreign element such as $\mathrm{Me}$ (mixed element) [47] and Ta (tantalum) [45]) is uniformly distributed in $\mathrm{W}$. The release of $\mathrm{He}$ in $\mathrm{W}$ and $\mathrm{W} 5 \mathrm{Re}$ is correlated to the mutation such as split and rupture of $\mathrm{He}$

Table 4 Thermal evolution ( $\leq 1273 \mathrm{~K}$ ) characteristics of He-ion irradiation induced defects in W and W5Re

\begin{tabular}{|c|c|c|c|}
\hline $\begin{array}{l}\text { Thermal evolu- } \\
\text { tion temperature } \\
\text { (K) }\end{array}$ & $\tau_{2}(\mathrm{ps})$ & $S$ parameter & Thermal evolution characteristics of irradiation-induced defects \\
\hline Post-irradiation & $\begin{array}{l}\sim 190 \text { ps for } \mathrm{W} \\
\text { and } \sim 130 \text { ps for } \\
\text { W5Re }\end{array}$ & Relative high & $\begin{array}{l}\text { Mono-vacancies dominated in W; a large amount of dislocation loops dominated in } \\
\text { W5Re }\end{array}$ \\
\hline RT-673 & $\sim 350 \mathrm{ps}$ & Relative high & $\begin{array}{l}\text { The growth of vacancy clusters at the expense of small vacancy clusters; He began to } \\
\text { dissociate from the small } \mathrm{He}_{\mathrm{n}} \mathrm{V}_{\mathrm{m}} \text { complexes }\end{array}$ \\
\hline $673-1073$ & $\sim 360 \mathrm{ps}$ & Relative low & $\begin{array}{l}\text { The formation of } \mathrm{V}_{4-8} \text { clusters and He bubbles; He dissociated from large } \mathrm{He}_{\mathrm{n}} \mathrm{V}_{\mathrm{m}} \text { com- } \\
\text { plexes; the vacancy clusters continued to coarsen and transformed into micro-voids; the } \\
\text { density of dislocations decreased }\end{array}$ \\
\hline $1073-1273$ & $\sim 240 \mathrm{ps}$ & High & $\begin{array}{l}\text { Medium-size vacancy clusters remains; He dissociated from large } \mathrm{He}_{\mathrm{n}} \mathrm{V}_{\mathrm{m}} \text { complexes and } \\
\text { He bubbles; the micro-voids began to anneal; obvious protrusions on the surface and } \\
\text { between the grain boundaries }\end{array}$ \\
\hline
\end{tabular}


bubbles at $1273 \mathrm{~K}$. In addition, the possible Re clusters in W5Re alloy may serve as the nucleation sites of He bubbles, which accelerates the swelling and protrusion formation of the grain boundary and surface.

The thermal evolution of defects in He-irradiated $\mathrm{W}$ and W5Re alloys are summarized in Table 4, which is divided into three stages: RT-673 K, 673-1073 K and 1073-1273 K. The irradiation cascade displacement induced mono-vacancies $(\sim 190 \mathrm{ps})$ in $\mathrm{W}$, together with a large amount of dislocation loops $(\sim 150 \mathrm{ps})$ in W5Re alloys. As the annealing temperature increases to $473 \mathrm{~K}$, the vacancy starts to migrate and aggregate to form the $\mathrm{V}_{\mathrm{n}}$ clusters $[13,40]$. The number " $\mathrm{n}$ " reaches 11 after $1273 \mathrm{~K}$ annealing. The research reported a strong binding energy of $\sim 4.5 \mathrm{eV}$ [48] between $\mathrm{He}$ atom and vacancy, which is $\sim 1 \mathrm{eV}$ between two He atoms at close separation distance in $\mathrm{W}$ matrix. Thus, as temperature increases, the vacancy-type defects continuously attract the incident $\mathrm{He}$ atoms to form $\mathrm{He}_{\mathrm{n}} \mathrm{V}_{\mathrm{m}}$ complexes by increasing the annealing temperature [10]. The growth of vacancy clusters results in large positron annihilation lifetime in these effective and open volume sites. However, the thermal desorption spectrum (TDS) results in Ref. [45] of He-irradiated W and W5Ta showed the desorption of He beginning from $450 \mathrm{~K}$. The desorption rate of He in TDS spectra increased with the annealing temperature until it reached the maximum desorption rate at $\sim 997 \mathrm{~K}$ [45]. This result is in well agreement with the data in this work. In this progress, the migration and aggregation of vacancies promote the formation of vacancy clusters. The coarsening vacancy clusters transform into micro-voids, in which the positron annihilation lifetime is even about $380 \mathrm{ps}$ [13]. Another small desorption peak is detected in the TDS spectrum at $1280 \mathrm{~K}$ in Ref. [45]. In the similar case, the positron lifetime is reduced to $240 \mathrm{ps}$, implying that the mediumsize vacancy clusters are attributed to the dissociation of large $\mathrm{He}_{\mathrm{n}} \mathrm{V}_{\mathrm{m}}$ complexes and the bursting of the He bubbles even the annealing of micro-voids remain in both $\mathrm{W}$ and W5Re.

\section{Conclusion}

The thermal evolution kinetics of He-irradiation induced defects in W and W5Re alloys of $0.83 \mathrm{dpa}, 1.62 \mathrm{dpa}$ and $\sim 1.45 \mathrm{dpa}$ were studied by positron annihilation spectroscopy. All irradiated samples were isochronal annealed from 373-1273 K for $1 \mathrm{~h}$. Similar thermal evolution characteristics of defects were shown in both W and W5Re, which could be divided into three stages: RT-673 K, 673-1073 K and 1073-1273 K. The conclusions of this work are summarized as follow.

1. He-ion irradiation introduced a lot of mono-vacancies (positron annihilation lifetime of $\sim 190 \mathrm{ps}$ ) in $\mathrm{W}$, together with dislocation loops $(\sim 150 \mathrm{ps})$ in W5Re alloys.
2. As the annealing temperature increased to $1078 \mathrm{~K}$, large-size vacancy clusters composed of 4-8 monovacancies formation by expensing of small vacancy clusters were detected in both $\mathrm{W}$ and W5Re. The vacancy-type defects in W5Re were more susceptible to the annealing temperature in IIR $(27-249 \mathrm{~nm})$ due to the formation of vacancy clusters-Re complexes.

3. After $1273 \mathrm{~K}$ annealing process, smaller positron annihilation lifetime ( $240 \mathrm{ps})$ was detected, which were attributed to the recovery of dislocation loops, the dissociation of large $\mathrm{He}_{\mathrm{n}} \mathrm{V}_{\mathrm{m}}$ complexes and the annealing of micro-voids in both $\mathrm{W}$ and W5Re.

4. Re clusters in W5Re alloy may serve as the nucleation sites of He bubbles, which promote a great plastic deformation such as swelling and protrusion formation on the surface.

Acknowledgements This work was financially supported by the National Key R\&D Project (Grant no. 2019YFA0210000) and the National Natural Science Foundation of China (Grant nos. U1732265, 11705213 and 11775235).

Funding Open access funding provided by University of Helsinki including Helsinki University Central Hospital.

Open Access This article is licensed under a Creative Commons Attribution 4.0 International License, which permits use, sharing, adaptation, distribution and reproduction in any medium or format, as long as you give appropriate credit to the original author(s) and the source, provide a link to the Creative Commons licence, and indicate if changes were made. The images or other third party material in this article are included in the article's Creative Commons licence, unless indicated otherwise in a credit line to the material. If material is not included in the article's Creative Commons licence and your intended use is not permitted by statutory regulation or exceeds the permitted use, you will need to obtain permission directly from the copyright holder. To view a copy of this licence, visit http://creativecommons.org/licenses/by/4.0/.

\section{References}

1. Federici G, Biel W, Gilbert MR, Kemp R, Taylor N, Wenninger R. European DEMO design strategy and consequences for materials. Nucl Fusion. 2017;57(9):26.

2. Bolt H, Barabash V, Federici G, Linke J, Loarte A, Roth J, Sato K. Plasma facing and high heat flux materials-needs for ITER and beyond. J Nucl Mater. 2002;307:43.

3. Liu YL, Lu EY, Song LG, Bai RY, Xu Q, Jin SX, Zhu T, Cao XZ, Zhang QL, Yuan DQ, Wang BY, Ge LQ. Depth synergistic effect of irradiation damage on tungsten irradiated by He-ions with various energies. J Nucl Mater. 2019;517:192.

4. Katoh Y, Snead LL, Garrison LM, Hu X, Koyanagi T, Parish CM, Edmondson PD, Fukuda M, Wang TH, Tanaka T, Hasegawa A. Response of unalloyed tungsten to mixed spectrum neutrons. J Nucl Mater. 2019;520:193.

5. Wang SW, Zhu XL, Cheng L, Guo WG, Liu M, Xu C, Yuan Y, Fu EG, Cao XZ, Lu GH. Effect of heavy ion pre-irradiation on blistering and deuterium retention in tungsten exposed to high-fluence deuterium plasma. J Nucl Mater. 2018;508:395. 
6. Fukuda M, Yabuuchi K, Nogami S, Hasegawa A, Tanaka T. Microstructural development of tungsten and tungsten-rhenium alloys due to neutron irradiation in HFIR. J Nucl Mater. 2014;455(1-3):460.

7. Tanno T, Hasegawa A, Fujiwara M, He JC, Nogami S, Satou M, Shishido T, Abe K. Precipitation of solid transmutation elements in irradiated tungsten alloys. Mater Trans. 2008;49(10):2259.

8. Tanno T, Hasegawa A, He JC, Fujiwara M, Nogami S, Satou M, Shishido T, Abe K. Effects of transmutation elements on neutron irradiation hardening of tungsten. Mater Trans. 2007;48(9):2399.

9. Xu A, Beck C, Armstrong DEJ, Rajan K, Smith GDM, Bagot PAJ, Roberts SG. Ion-irradiation-induced clustering in W-Re and $\mathrm{W}-\mathrm{Re}-\mathrm{Os}$ alloys: a comparative study using atom probe tomography and nanoindentation measurements. Acta Mater. 2015;87:121.

10. Luo FF, Guo LP, Lu DP, Wang JW, Zheng ZC, Zhang WP, Shen ZY. TEM observation of bubbles induced by single and sequential $\mathrm{He} / \mathrm{H}$ irradiation in tungsten. Fusion Eng Des. 2017; $125: 463$.

11. Cao XZ, Song LG, Jin SX, Zhang RG, Wang BY, Wei L. Advances in applications of positron annihilation spectroscopy to investigating semiconductor microstructures. Acta Phys Sin. 2017;66(2):027801.

12. Cao XZ, Zhu T, Jin SX, Kuang P, Zhang P, Lu EY, Gong YH, Guo LP, Wang BY. Detection of helium in irradiated $\mathrm{Fe} 9 \mathrm{Cr}$ alloys by coincidence doppler broadening of slow positron annihilation. Appl Phys A Mater Sci Process. 2017;123(3):1.

13. Nambissan PMG, Sen P. Positron-annihilation study of the annealing behavior of alpha-induced defects in tungsten. Radiat Eff Defects Solids. 1992;124(2):215.

14. Xu Q, Ishizaki T, Sato K, Yoshiie T, Nagata S. Coincidence doppler broadening of positron annihilation radiation for detection of helium in irradiated $\mathrm{Ni}$ and $\mathrm{Cu}$. Mater Trans. 2006;47(11):2885.

15. Kapser S, Balden M, Silva TF, Elgeti S, Manhard A, Schmid $\mathrm{K}$, Schwarz-Selinger T, Toussaint U. Influence of sub-surface damage evolution on low-energy-plasma-driven deuterium permeation through tungsten. Nucl Fusion. 2018;58(5):1.

16. Ogorodnikova OV, Dubov LY, Stepanov SV, Terentyev D, Funtikov YV, Shtotsky YV, Stolbunov VS, Efimov V, Gutorov K. Annealing of radiation-induced defects in tungsten: positron annihilation spectroscopy study. J Nucl Mater. 2019;517:148.

17. Sato K, Hirosako A, Ishibashi K, Miura Y, Xu Q, Onoue M, Fukutoku Y, Onitsuka T, Hatakeyama M, Sunada S, Yoshiie T. Quantitative evaluation of hydrogen atoms trapped at single vacancies in tungsten using positron annihilation lifetime measurements: experiments and theoretical calculations. J Nucl Mater. 2017;496:9.

18. Ogorodnikova OV, Tyburska B, Alimov VK, Ertl K. The influence of radiation damage on the plasma-induced deuterium retention in self-implanted tungsten. J Nucl Mater. 2011;415(1):S661

19. Hu XX, Koyanagi T, Fukuda M, Katoh Y, Snead LL, Wirth BD. Defect evolution in single crystalline tungsten following low temperature and low dose neutron irradiation. J Nucl Mater. 2016;470:278.

20. Lynn KG, Dickman JE, Brown WL, Robbins MF, Bonderup E. Vacancies studied by positron-annihilation with high-momentum core electrons. Phys Rev B. 1979;20(9):356.

21. Nagai Y, Tang Z, Ohkubo H, Takadate K, Hasegawa M. Elemental analysis of positron affinitive site in materials by coincidence doppler broadening spectroscopy. Radiat Phys Chem. 2003;68(3):381.
22. Richard AF. Theory of positron annihilation in solids. Rev Mod Phys. 1965;28(3):308.

23. Hugenschmidt C. Positrons insurface physics. Surf Sci Rep. 2016;71(4):547.

24. Jin SX, Zhang P, Lu EY, Guo LP, Wang BY, Cao XZ. Correlation between $\mathrm{Cu}$ precipitates and irradiation defects in $\mathrm{Fe}-\mathrm{Cu}$ model alloys investigated by positron annihilation spectroscopy. Acta Mater. 2016;103:658

25. Zhang SS, Cizek J, Yao ZJ, Oleksandr M, Kong XS, Liu CS, Dijk NV. Self healing of radiation-induced damage in Fe-Au and $\mathrm{Fe}-\mathrm{Cu}$ alloys: Combining positron annihilation spectroscopy with tem and ab initio calculations. J Alloy Compd. 2020;817:10.

26. Stoller RE, Toloczko MB, Was GS, Certain AG, Dwaraknath S, Garner FA. On the use of SRIM for computing radiation damage exposure. Nucl Instrum Methods Phys. 2013;310:75.

27. ASTM E521-96 (2009) e1. Standard practice for neutron radiation damage simulation by charged-particle irradiation, ASTM International, West Conshohocken, PA. https://www.astm.org/

28. Kansy J. Microcomputer program for analysis of positron annihilation lifetime spectra. Nucl Instrum Method A. 1996;374(2):235.

29. Staab TEM, Somieski B, KrauseRehberg R. The data treatment influence on the spectra decomposition in positron lifetime spectroscopy part 2. The effect of source corrections. Nucl Instrum Methods A. 1996;381(1):141.

30. Sato K, Tamiya R, Xu Q, Tsuchida H, Yoshiie T. Detection of deuterium trapping sites in tungsten by thermal desorption spectroscopy and positron annihilation spectroscopy. Nucl Mater Eng. 2016;9:554.

31. Brandt W, Dupasquier A. Positron solid-state physics. Amsterdam: North-Holland Publishing Company; 1983. p. 690.

32. Wang K, Deng AH, Gong M, Lu XB, Zhang YY, Liu X. Effect on microstructure of tungsten under helium ions irradiation with multiple energy. Acta Metall Sin. 2017;53(1):70.

33. Nemoto Y, Hasegawa A, Satou M, Abe K. Microstructural development of neutron irradiated W-Re alloys. J Nucl Mater. 2000;283:1144

34. Hu XX, Parish CM, Wang K, Koyanagi T, Eftink BP, Katoh Y. Transmutation-induced precipitation in tungsten irradiated with a mixed energy neutron spectrum. Acta Mater. 2019;165:51.

35. Puska MJ, Nieminen RM. Defect spectroscopy with positronsa general calculational method. J Phys F. 1983;13(2):333.

36. Naidu SV, Gupta AS, Sen P. Defect studies in alpha-irradiated and deformed niobium by positron annihilation. Solid State Commun. 1985;55(1):22.

37. Zibrov M, Egger W, Heikinheimo J, Mayer M, Tuomisto F. Vacancy cluster growth and thermal recovery in hydrogenirradiated tungsten. J Nucl Mater. 2020;531:7.

38. King HW. Quantitative size-factors for metallic solid solutions. J Mater Sci. 1966;1(1):79.

39. Lloyd MJ, Abernethy RG, Gilbert MR, Griffiths I, Bagot PAJ, Nguyen-Manh D, Moody MP, Armstrong DEJ. Decoration of voids with rhenium and osmium transmutation products in neutron irradiated single crystal tungsten. Scripta Mater. 2019;173:96.

40. Lhuillier PE, Barthe MF, Desgardin P, Egger W, Sperr P. Positron annihilation studies on the nature and thermal behaviour of irradiation induced defects in tungsten. Phys Status Solidi C. 2009;6(11):2329.

41. Xie HX, Xu K, Lu GH, Yu T, Yin FX. Trapping of hydrogen and helium at an $\{110\}<111>$ edge dislocation in tungsten. J Nucl Mater. 2017;484:270.

42. Chen WQ, Wang XY, Xiao XZ, Qu SL, Jia YZ, Cui W, Cao XZ, Xu B, Liu W. Characterization of dose dependent 
mechanical properties in helium implanted tungsten. J Nucl Mater. 2018;509:260.

43. Bakaev A, Terentyev D, Grigorev P, Posselt M, Zhurkin EE. Ab initio study of interaction of helium with edge and screw dislocations in tungsten. Nucl Instrum Methods Phys. 2017;393:150.

44. Song LG, Wang BY, Zhu T, Gong YH, Xu Q, Guo LP, Jin SX, Zhang P, Song YM, Cao XZ. Evolution of defects with isochronal annealing in helium-irradiated 316L studied by slow positron beam. Nucl Instrum Methods Phys. 2020;467:80.

45. Zhou H, Yu JG, Han WJ, Cheng L, Chen CA, Zhu KG. Large plastic deformation blistering and helium retention in 5\% tantalum doped tungsten under $60 \mathrm{keV}$ helium ions implantation. Fusion Eng Des. 2018;134:43.

46. Sorokin MV, Ryazanov AI. Effect of elastic stress field near grain boundaries on the radiation induced segregation in binary alloys. J Nucl Mater. 2006;357(1-3):82.

47. Kalin BA, Chernov II, Kalashinikov AN, Ananin VM. Behavior of ion-implanted helium and structural changes in nickel-base alloys under long-time exposure at elevated temperatures. J Nucl Mater. 1999;271:333.

48. Becquart CS, Domain C. A density functional theory assessment of the clustering behaviour of $\mathrm{He}$ and $\mathrm{H}$ in tungsten. J Nucl Mater. 2009;386:109.

Publisher's Note Springer Nature remains neutral with regard to jurisdictional claims in published maps and institutional affiliations.

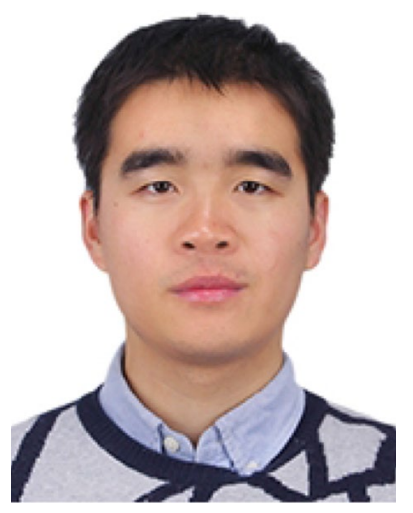

Dr. Er-Yang Lu is a postdoctoral researcher in University of Helsinki, Finland. He received the $\mathrm{Ph}$. D. degree from University of Chinese academy of Sciences at 2016. After that, he has been awarded as a postdoctoral research fellow from Academy of Finland and working in Helsinki Accelerator Laboratory, Finland. Dr. Lu's research interests includes positron physics and spectroscopy development, materials characterization, irradiation effects and helium behavior in metals and innovative alloys.

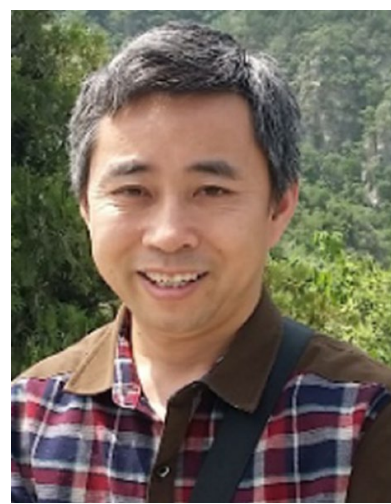

Dr. Xing-Zhong Cao is currently a professor in the Institute of High Energy Physics (IHEP), Chinese Academy Sciences (CAS), China, who received his $\mathrm{Ph} . \mathrm{D}$. degree from Lanzhou University, China, in 2004. Before joining IHEP in 2010, he has worked at KEK and Kyoto University of Japan for four years. Dr. Cao's research interests include the techniques development of Positron annihilation spectroscopy and slow positron beam, and their application research on the characterization of the characteristics of lattice defects in solid materials, and on the studying of the internal relationship between the macroscopic properties of materials and the atomic scale microscopic defect structure. 